\title{
Caesium and iodine release from spent mixed oxide fuels under repository relevant conditions: Initial leaching results
}

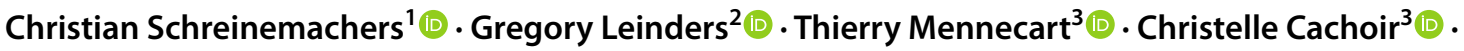

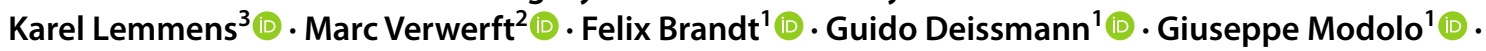 \\ Dirk Bosbach ${ }^{1}$ (1)
}

Received: 23 November 2021 / Accepted: 27 January 2022 / Published online: 9 February 2022

(c) The Author(s) 2022

\begin{abstract}
Autoclave leaching experiments are conducted on three well-characterised, irradiated, and cladded mixed oxide fuel-rod segments with burnups ranging from $29 \mathrm{GWd} / \mathrm{t}_{\mathrm{HM}}$ to $52 \mathrm{GWd} / \mathrm{t}_{\mathrm{HM}}$ to investigate the instant release fraction of fission gases and long-lived fission products and to assess the long-term fuel matrix corrosion. The segments are exposed to bicarbonate solutions as reference groundwater at neutral $\mathrm{pH}$ and a synthetic young cementitious water at $\mathrm{pH} 13.5$ under reducing atmosphere ( $4 \mathrm{vol} \% \mathrm{H}_{2}$ in $\mathrm{Ar}$ at 40 bar pressure), since 2018. The initial leaching results for the fission products caesium and iodine as representative elements of the instant release fraction were found to depend on the leachate composition as well as on the fuel burnup.
\end{abstract}

\section{Introduction}

Disposal in a deep geological repository (DGR) based on a multi-barrier concept is considered as the safest and most sustainable option for the management of spent nuclear fuels (SNFs) in many countries. Demonstrating the long-term safety of a DGR for SNFs over assessment time-frames of up to one million years requires a profound understanding of the corrosion behaviour of SNF coming into contact with groundwater, when the waste canister is eventually breached. During the last decades, multiple studies addressed this topic, leading to a good phenomenological understanding of the long-term behaviour of SNF in a DGR [1-5]. However, various processes contributing to the (radiolytic) matrix corrosion of SNF in the generally reducing repository

Christian Schreinemachers

c.schreinemachers@fz-juelich.de

1 Forschungszentrum Jülich GmbH, Institute of Energy and Climate Research, IEK-6: Nuclear Waste Management and Reactor Safety, 52425 Jülich, Germany

2 Belgian Nuclear Research Centre (SCK CEN), Institute for Nuclear Materials Science, Boeretang 200, $2400 \mathrm{Mol}$, Belgium

3 Belgian Nuclear Research Centre (SCK CEN), Institute for Environment, Health and Safety, Boeretang 200, 2400 Mol, Belgium environment are still not fully understood, and corrosion data on spent mixed oxide (MOX) fuels are scarce to date.

The SF-ALE project (spent fuel autoclave leaching experiments) was initiated between the Belgian Nuclear Research Centre (SCK CEN) and Forschungszentrum Jülich GmbH to investigate effects of environmental conditions on the corrosion of various types of SNF. Within SF-ALE, the release of radionuclides from irradiated MOX fuel-rod segments exposed to a bicarbonate solution (BIC) as reference groundwater and a synthetic young cementitious water (YCW) under reducing atmosphere is investigated. The experimental phase started in 2017 and consists of three work packages: (1) MOX post-irradiation examination, (2) autoclave leaching study, and (3) post-leaching characterisation. In this work, we present initial results of the release of the fission products caesium and iodine from the MOX during the first two years of leaching.

\section{Materials and methods}

\section{MOX fuel-rod properties and sample segments}

A MOX fuel-rod with Zircaloy-4 cladding is studied within SF-ALE. The fuel pellets were fabricated by Belgonucleaire (Dessel, Belgium) via the MIMAS process [6]. Initially, it contained a Pu molar metal fraction of $14 \mathrm{~mol} \%$ and an 
oxygen to metal ratio of 1.99 [7]. The fuel-rod was irradiated in the Belgian reactors BR-3 and BR-2 for a total duration of 1048 days between 1986 and 2011, employing an average linear power rating of about $210 \mathrm{~W} / \mathrm{cm}$ with a maximum of about $325 \mathrm{~W} / \mathrm{cm}$. Its burnup was estimated non-destructively by $\gamma$-spectrometry, taking a fission energy of $208 \mathrm{MeV} /$ fission and an axial depending ${ }^{137} \mathrm{Cs}$ in-pile decay factor into account [8]; the result is shown in Fig. 1a.

Three fuel-rod segments with burnups of about $50 \mathrm{GWd} / \mathrm{t}_{\mathrm{HM}}, 52 \mathrm{GWd} / \mathrm{t}_{\mathrm{HM}}$, and $29 \mathrm{GWd} / \mathrm{t}_{\mathrm{HM}}$ were selected for the autoclave leaching experiments. The segments are indicated in Fig. 1a and labelled with DIS1, DIS2 and DIS3, respectively. During the segment preparation, the fuel-rod was cut in such a way that they halved a pellet. The segments used in the leaching experiments have lengths of $24 \mathrm{~mm}$ and contain two half pellets and one entire pellet in between, as schematically shown in Fig. 1 b.

\section{Autoclave leaching experiments}

The cladded fuel segments are exposed to either YCW or $\mathrm{BIC}$, the latter has an initial $\mathrm{pH}$ of 7.4 and contains $1 \mathrm{mmol} / \mathrm{L}$ $\mathrm{NaHCO}_{3}$ and $19 \mathrm{mmol} / \mathrm{L} \mathrm{NaCl}$. The YCW has a pH of 13.5 and contains $\mathrm{K}, \mathrm{Na}$, and $\mathrm{Ca}$, as well as traces of $\mathrm{Si}, \mathrm{Al}$ and $\mathrm{B}$, with contents comparable to those reported by Ref. [9]. In order to investigate the influence of the leachate on the dissolution behaviour, the high burnup segments (DISI and $D I S 2)$ are leached in YCW and BIC, respectively. The segment with the lower burnup (DIS3) is exposed to BIC to study the influence of the fuels' burnup.

The experimental set-up is based on a design developed at the Karlsruhe Institute of Technology [10] and the experiments are carried out at room temperature in autoclaves manufactured by Berghof $\left(V_{\text {total }}=250 \mathrm{~mL}\right)$ [7]. The latter contain a titanium liner, which is filled with the fuel-rod segment ( $12.9 \mathrm{~g}$ to $15.7 \mathrm{~g}$ ) mounted in a holder, the leachate $(200 \mathrm{~mL})$, and an Ar: $\mathrm{H}_{2}$ gas atmosphere (96:4, $p=40$ bar).

The autoclave experiments were initiated in September 2018 and two leaching phases with durations of 18 months were envisaged. Samplings of gas $(50 \mathrm{~mL})$ and leachate $(10 \mathrm{~mL})$ are carried out within the course of each phase. The first sampling was performed after 5 days and the solution was replaced with fresh leachate. Further samplings were done after 3 weeks, 3 months, and 9 months. A sampling and replacement of the autoclaves' titanium insert and the leachate was foreseen after 18 months as end of the first phase. The sampling was shifted to month 20 and the pressure was reduced to 4 bar as safety precaution until the inserts could be replaced (SARS-CoV-2 interruption), which was done after 24 months. The leachate was sampled prior to the exchange of the inserts. Afterwards, fresh leachate was added and the $\mathrm{Ar}: \mathrm{H}_{2}$ pressure was set to $40 \mathrm{bar}$. The used inserts underwent an acidic rinsing and the rinsing solution was analysed as well. The transition from the first to the second leaching phase is described in more detail elsewhere [8]. Within phase two, samplings were performed after total durations of 25 months, 30 months, and 36 months. A last sampling is foreseen after 42 months and will complete the second leaching phase in March 2022.

\section{Characterisation of leaching samples}

Gas samples are analysed to study the release of the fission gases $\mathrm{Kr}$ and $\mathrm{Xe}$, combined with the additional monitoring of $\mathrm{H}_{2}, \mathrm{~N}_{2}$ and $\mathrm{O}_{2}$ [8]. The aqueous samples are analysed for about 30 relevant actinides, fission and activation products by $\alpha$ - and $\gamma$-spectrometry, liquid scintillation counting, as well as inductive coupled plasma mass spectrometry (ICP-MS).

In this work, leaching results of the fission products caesium and iodine are presented. The molar caesium concentrations are based on ICP-MS analyses of ${ }^{133} \mathrm{Cs}$ and
Fig. 1 Burnup of the irradiated MOX fuel-rod as function of the axial position, as well as regions of segments in use within the leaching phases of SF-ALE (a). Schematic representation of a fuel-rod segment studied within the autoclave leaching experiments (b)
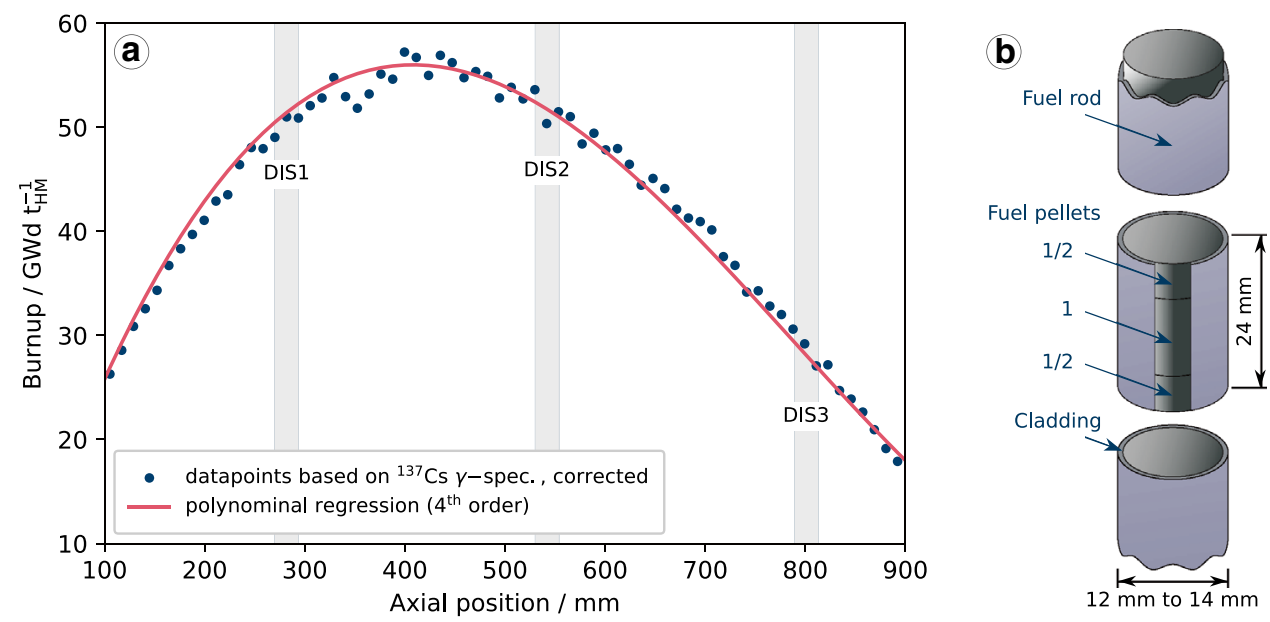
$\gamma$-spectrometry results of ${ }^{134} \mathrm{Cs}$ and ${ }^{137} \mathrm{Cs}$, while the molar iodine concentrations originate from ICP-MS analyses of ${ }^{129} \mathrm{I}$. The data of ${ }^{137} \mathrm{Cs}$ and ${ }^{129} \mathrm{I}$ were converted into molar amounts and normalised to the initial molar amounts of the corresponding nuclides in the fuel-rod segment in order to determine their inventory in the aqueous phase (FIAP). The initial amounts of the nuclides originate from depletion calculations [8].

\section{Results}

The burnup results (Fig. 1) show an axial dependency caused by different flux profiles of the reactors BR-2 and BR-3. Consequently, the nuclide inventory required to calculate the FIAPs depends on the axial position as well. The initial caesium content in the segments DIS1,DIS2 and DI3 was $2.75 \mathrm{mg} / \mathrm{g}_{\text {fuel }}, 2.82 \mathrm{mg} / \mathrm{g}_{\text {fuel }}$ and $1.58 \mathrm{mg} / \mathrm{g}_{\text {fuel }}$, respectively; the ${ }^{129} \mathrm{I}$ content was determined to be $0.31 \mathrm{mg} / \mathrm{g}_{\text {fuel }}$, $0.32 \mathrm{mg} / \mathrm{g}_{\text {fuel }}$, and $0.18 \mathrm{mg} / \mathrm{g}_{\text {fuel }}[8]$.

The leaching results for caesium and iodine obtained in the first leaching phase of SF-ALE are summarised in Fig. 2. FIAPs presented in Fig. 2 are semi-cumulative: The datapoint determined in the replaced leachate after 5 days was added as offset to the data-points of the renewed leachate.

\section{Caesium release}

After an exposure time of 5 days, the highest caesium content was found in YCW (Fig. 2a, b). The concentrations determined in the renewed YCW were relatively constant from day 21 until the end of leaching phase one and correspond to an average caesium FIAP of $10.6 \%$ for DISI. In the experiments in BIC, a proportional behaviour was observed and a steady state was reached after 82 days of exposure with average caesium FIAPs of $8.6 \%$ and $1.9 \%$ for DIS2 and $D I S 3$, respectively.

Sorbed Caesium masses were determined based on the analysis results of the rinsing solutions. The results were converted into the corresponding caesium FIAPs and taken into account in the last data-points presented in Fig. 2b, but with contributions ranging from $0.01 \%$ to $0.03 \%$ they can be considered as negligible.

\section{lodine release}

Similar iodine concentrations were obtained in the YCW and BIC leaching samples of the high burnup segments after 5 days (Fig. 2c, d). In the renewed leachates of both experiments, the concentrations increased and reached maxima after an exposure of 82 days, corresponding to FIAPs of $7.0 \%$ and $13.1 \%$ for DISI and DIS2, respectively. The leaching of segment DIS3 took 271 days until a maximum with a FIAP of $5.0 \%$ was observed. A decrease within the uncertainty ranges was noted after surpassing the maxima, which was more pronounced in BIC. However, it occurred for all three experiments and FIAPs of $6.5 \%, 11.9 \%$ and $4.4 \%$ were determined after 734 days for DIS1, DIS 2 and $D I S 3$, respectively.

Due to the instability of iodine in the acidic rinsing solution, it was not analysed in the rinsing samples.
Fig. 2 Molar caesium and iodine concentrations obtained in autoclave leaching experiments on spent MOX fuels under reducing conditions (4 vol\% $\mathrm{H}_{2}$ in Ar at 40 bar pressure; YCW: young cementitious water, BIC: bicarbonate solution) as function of the exposure time $(\mathbf{a}, \mathbf{c})$ and resulting FIAPs for both elements $(\mathbf{b}, \mathbf{d})$. The shaded areas correspond to the 4 bar interval at the end of leaching phase one. Please note that in the top figures $(\mathbf{a}, \mathbf{c})$ the leachate renewal took place after the first data-point, which is disconnected from the subsequent data-points. The bottom row figures $(\mathbf{b}, \mathbf{d})$ represent the integral release (i.e. the release of the first 5 days is added to the subsequent release)

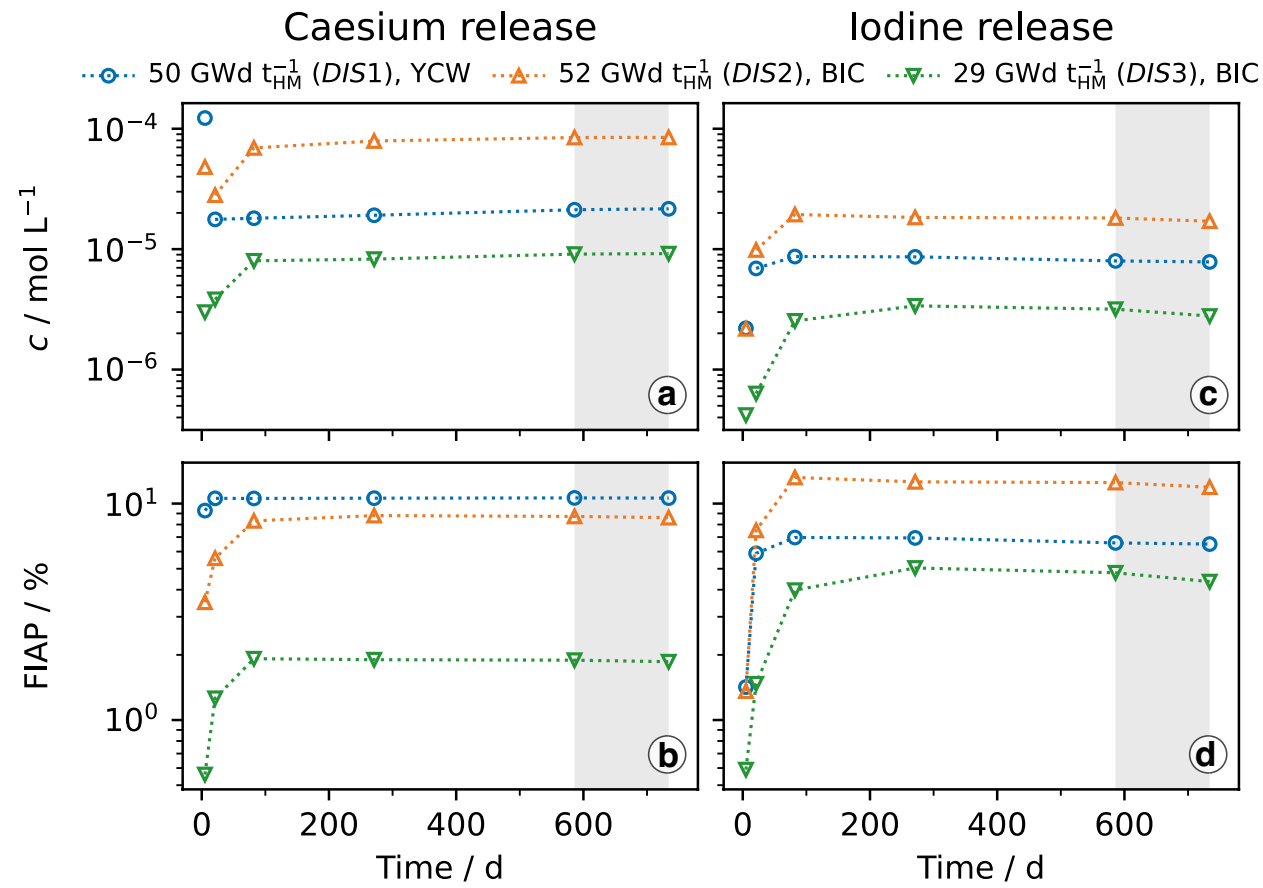


Consequently, the FIAPs presented in Fig. 2d do not consider any sorption of iodine to the autoclave liners, which in turn would also be not expected.

\section{Discussion}

In all experiments, a fast initial release of caesium and iodine was observed, reaching nearly constant concentration levels after 82 days (Fig. 2). An influence of the leachate composition on the leaching behaviour of caesium and iodine from irradiated MOX under reducing atmosphere was revealed by several observations: The instant release of caesium occurred within 21 days in YCW, which was delayed to 82 days and by a factor of about 0.8 less pronounced in BIC for comparable burnups of about $50 \mathrm{GWd} / \mathrm{t}_{\mathrm{HM}}$. The release of iodine behaved inversely, by a factor of about 1.9 larger fractions iodine were monitored in BIC as compared to YCW, but the dissolution rates were less affected by the leachate variation than the caesium dissolution rates for segments with similar burnups.

A comparison of the leaching results of the segments with varying burnups in BIC shows an influence on the iodine leaching behaviour by a prolonged release within 271 days for the lower burnup of $29 \mathrm{GWd} / \mathrm{t}_{\mathrm{HM}}$. Moreover, the iodine FIAP was about a factor of 2.6 higher in the leachate of the segment with a burnup of $52 \mathrm{GWd} / \mathrm{t}_{\mathrm{HM}}$, which was in the case of caesium a factor of about 4.6 higher and hence more pronounced.

\section{Conclusions}

Autoclave leaching results showed an influence of the leaching medium and the fuels' burnup on its leaching behaviour for the release of the fission products caesium and iodine from irradiated, cladded MOX fuel-rod segments under reducing atmosphere. Caesium and iodine release occurred for a fuel burnup of about $50 \mathrm{GWd} / \mathrm{t}_{\mathrm{HM}}$ rapidly in less than 82 days in YCW and BIC. For a lower burnup of $29 \mathrm{GWd} / \mathrm{t}_{\mathrm{HM}}$ the caesium release rate into BIC was comparable, while iodine release occurred in less than 271 days from the identical segment in the same medium. Furthermore, no significant caesium sorption was noted, demonstrating that caesium remains in aqueous phase for solutions with initial $\mathrm{pH}$ values of 7.4 and 13.5 during a time-frame of about two years.

Acknowledgments The authors gratefully acknowledge the technical support from B. Gielen, P. Schroeders, G. Cools and H. Van Eyck, as well as the analytical services of SCK CEN.
Funding Open Access funding enabled by the Deutsche Forschungsgemeinschaft (DFG, German Research Foundation) - 491111487, and organised by the Projekt DEAL.

Data availability The data of the current study are available from the corresponding author on reasonable request.

\section{Declarations}

Conflict of interest The authors declare that they have no known competing financial interests or personal relationships that could have appeared to influence the work reported in this paper.

Open Access This article is licensed under a Creative Commons Attribution 4.0 International License, which permits use, sharing, adaptation, distribution and reproduction in any medium or format, as long as you give appropriate credit to the original author(s) and the source, provide a link to the Creative Commons licence, and indicate if changes were made. The images or other third party material in this article are included in the article's Creative Commons licence, unless indicated otherwise in a credit line to the material. If material is not included in the article's Creative Commons licence and your intended use is not permitted by statutory regulation or exceeds the permitted use, you will need to obtain permission directly from the copyright holder. To view a copy of this licence, visit http://creativecommons.org/licenses/by/4.0/.

\section{References}

1. P. Carbol, P. Fors, S. Van Winckel, K. Spahiu, Corrosion of irradiated MOX fuel in presence of dissolved $\mathrm{H}_{2}$. J. Nucl. Mater. 392(1), 45-54 (2009). https://doi.org/10.1016/j.jnucmat.2009.03.044

2. C. Jégou, R. Caraballo, J. De Bonfils, V. Broudic, S. Peuget, T. Vercouter, D. Roudil, Oxidizing dissolution of spent MOX47 fuel subjected to water radiolysis: Solution chemistry and surface characterization by Raman spectroscopy. J. Nucl. Mater. 399(1), 68-80 (2010). https://doi.org/10.1016/j.jnucmat.2010.01.004

3. L. Johnson, I. Günther-Leopold, J. Kobler Waldis, H.P. Linder, J. Low, D. Cui, E. Ekeroth, K. Spahiu, L.Z. Evins, Rapid aqueous release of fission products from high burn-up LWR fuel: Experimental results and correlations with fission gas release. J. Nucl. Mater. 420(1-3), 54-62 (2012). https://doi.org/10.1016/j.jnucm at.2011.09.007

4. M. Magnin, C. Jégou, R. Caraballo, V. Broudic, M. Tribet, S. Peuget, Z. Talip, Oxidizing dissolution mechanism of an irradiated MOX fuel in underwater aerated conditions at slightly acidic pH. J. Nucl. Mater. 462, 230-241 (2015). https://doi.org/ 10.1016/j.jnucmat.2015.03.029

5. M. Odorowski, C. Jégou, L. De Windt, V. Broudic, S. Peuget, M. Magnin, M. Tribet, C. Martin, Oxidative dissolution of unirradiated Mimas MOX fuel (U/Pu oxides) in carbonated water under oxic and anoxic conditions. J. Nucl. Mater. 468, 17-25 (2016). https://doi.org/10.1016/j.jnucmat.2015.09.059

6. D. Haas, MOX fuel fabrication experience at Belgonuclèaire. In: Technical committee meeting on recycling of plutonium and uranium in water reactor fuel, pp. 77-89 (1997)

7. T. Mennecart, G. Leinders, C. Cachoir, G. Cornelis, G. Verpoucke, G. Modolo, D. Bosbach, K. Lemmens, M. Verwerft, First phase of the Spent Fuel Autoclave Leaching Experiments (SF-ALE) at SCK CEN. In: Proceedings of GLOBAL/TOPFUEL 2019, pp. 1-8. American Nuclear Society (2019). Seattle (WA), USA

8. G. Leinders, M. Verwerft, J. Eysermans, T. Mennecart, C. Cachoir, K. Lemmens, C. Schreinemachers, G. Deissmann, G. 
Modolo, D. Bosbach, Leaching experiments on UOX and MOX spent fuel: Results and prospects of the SF-ALE project at SCK CEN. In: Proceedings of TOPFUEL 2021. European Nuclear Society (2021). https://doi.org/10.5281/zenodo.5718461

9. K. Ferrand, M. Klinkenberg, S. Caes, J. Poonoosamy, W. Van Renterghem, J. Barthel, K. Lemmens, D. Bosbach, F. Brandt, Dissolution kinetics of international simple glass and formation of secondary phases at very high surface area to solution ratio in young cement water. Materials 14(5), 1254 (2021). https://doi.org/ $10.3390 / \mathrm{ma} 14051254$
10. E. González-Robles, V. Metz, D.H. Wegen, M. Herm, D. Papaioannou, E. Bohnert, R. Gretter, N. Müller, R. Nasyrow, W. de Weerd, T. Wiss, B. Kienzler, Determination of fission gas release of spent nuclear fuel in puncturing test and in leaching experiments under anoxic conditions. J. Nucl. Mater. 479, 67-75 (2016). https://doi.org/10.1016/j.jnucmat.2016.06.035 